\title{
Canine Leishmaniasis: An Overview of the Current Status and Strategies for Control
}

\author{
Raul Rio Ribeiro $\mathbb{D}^{1},{ }^{1}$ Marilene Suzan Marques Michalick, ${ }^{2}$ \\ Manoel Eduardo da Silva, ${ }^{3}$ Cristiano Cheim Peixoto dos Santos, ${ }^{4}$ \\ Frédéric Jean Georges Frézard, ${ }^{4}$ and Sydnei Magno da Silva ${ }^{5,6}$
}

\author{
${ }^{1}$ Departamento de Medicina Veterinária, Universidade Federal de Juiz de Fora, Campus Juiz de Fora, \\ Rua José Lourenço Kelmer s/n, Campus Universitário, Bairro São Pedro, 36036-900 Juiz de Fora, MG, Brazil \\ ${ }^{2}$ Departamento de Parasitologia, Instituto de Ciências Biológicas, Universidade Federal de Minas Gerais, Belo Horizonte, MG, Brazil \\ ${ }^{3}$ Empresa de Pesquisa Agropecuária de Minas Gerais (EPAMIG), Campo Experimental de Pitangui, \\ ITAC/EPAMIG, Pitangui, MG, Brazil \\ ${ }^{4}$ Departamento de Fisiologia e Biofísica, Instituto de Ciências Biológicas, Universidade Federal de Minas Gerais, \\ Belo Horizonte, MG, Brazil \\ ${ }^{5}$ Departamento de Parasitologia, Universidade Federal de Uberlândia (UFU), Uberlândia, MG, Brazil \\ ${ }^{6}$ BrasiLeish Group, Study Group on Animal Leishmaniasis, Belo Horizonte, MG, Brazil
}

Correspondence should be addressed to Raul Rio Ribeiro; raul.rio@uff.edu.br

Received 2 December 2017; Accepted 18 February 2018; Published 29 March 2018

Academic Editor: Francesca Mancianti

Copyright (C) 2018 Raul Rio Ribeiro et al. This is an open access article distributed under the Creative Commons Attribution License, which permits unrestricted use, distribution, and reproduction in any medium, provided the original work is properly cited.

\begin{abstract}
Canine leishmaniasis (CanL) is a vector-borne disease caused by Leishmania infantum and is transmitted by female phlebotomine sand flies primarily between animals and secondarily to humans. The course of infection may be different from one individual dog to another, ranging from spontaneous cure to acute evolution that leads to death, if proper management and therapy are not adopted. A parasitological cure is rarely achieved and clinical recurrences in CanL are frequent. Vaccination associated with the use of topical insecticides is undoubtedly the most effective form of prevention and control of the disease. In order to integrate the most important scientific knowledge of the literature in one objective publication, this review proposes a short overview of the main points of CanL.
\end{abstract}

\section{Introduction}

Leishmaniasis is a group of diseases produced by the invasion of protozoan parasites of the genus Leishmania into the mononuclear phagocyte system of mammalian hosts. They are transmitted primarily by the hematophagous activities of female phlebotomine sand flies belonging to the genera Lutzomyia (New World) and Phlebotomus (Old World). These neglected diseases are prevalent in at least 98 countries and 3 territories on 5 continents, of which the majority are underdeveloped countries $[1,2]$. Approximately 12 million people are infected with a species of Leishmania at any given time [2].

About 70 species of mammals, including humans, are considered vertebrate hosts of different species of Leishmania around the world, and some of them are reservoirs of the parasite in nature [1]. Although the natural infection in rodents $[3,4]$ and canids [5-10] is more common, the parasite is able to infect xenarthrans [11, 12], hyraxes [13], marsupials [14], chiropterans [15-17], lagomorphs [18-21], procyonids [11, 22], felids [23-26], Perissodactyla [27, 28], and primates [11, 29]. Determining the precise role played by each host in the transmission cycle remains a challenge.

These protozoans cause a wide variety of clinical forms ranging in severity from self-healing cutaneous leishmaniasis (CL) to fatal disseminated visceral leishmaniasis (VL) [30]. Among the recognized clinical forms of the disease, kala-azar, or $\mathrm{VL}$, is the most severe and progressive form, as it is almost always fatal if untreated. In the Indian subcontinent and 
East Africa, VL is transmitted between people (i.e., anthroponotic). In the rest of the world, particularly in the highlands of China, Central Asia, the Middle East, Transcaucasia, the Mediterranean, and Central and South America, VL is a zoonosis; that is, it is transmitted between animals and is secondarily transmitted to people [31]. Leishmania infantum has been identified as the main aetiologic agent of canine leishmaniasis (CanL) [32], which is a major global zoonosis that is potentially fatal to humans and dogs [32], and it is one of the world's most important emerging diseases [1].

\section{Transmission and Life Cycle}

Since the discovery of CanL in Tunisia, by Nicolle and Comte (1908) [33], the dog has been implicated as a major reservoir of the etiological agent of VL, playing a key role in its transmission [34]. Other infected mammals, such as the crabeating fox Cerdocyon thous and opossums Didelphis spp., are suspected as playing an epidemiologic role in transmission, but the confirmation of these hosts as reservoirs and their impact on the transmission cycle is unknown [7, 35, 36]. Maned wolves (Chrysocyon brachyurus) and bush dogs (Speothos venaticus) can be infectious to sand fly vectors even in the absence of clinical signs, but the epidemiological relevance of these findings has not yet been established [29, 37, 38]. The susceptibility of domestic cats (Felis catus) to infection by L. infantum, the clinical outcome, and their importance for the maintenance of the life cycle of the parasite are poorly understood [39]. It seems that the immune response in cats is effective enough to control the infection and confer a certain degree of resistance, if there are not immunosuppressive events such as retroviruses [Feline Immunodeficiency Virus (FIV) and Feline Leukemia Virus (FeLV)] [40], cancer, autoimmune disease, and others. Though infected domestic cats could be infectious to competent vectors of $L$. infantum, the confirmation of these hosts as accidental hosts and as secondary or alternative reservoirs requires further study [39].

Among the over 800 phlebotomine sand fly species estimated to exist, about 98 species are currently proven or suspected vectors of leishmaniasis [41]. Like many other vectorborne diseases, transmission originates during blood meals that females require to develop a batch of eggs. The parasite has a digenetic life cycle, alternating between a mammalian host and insect vectors. In short and according to the literature, when a sand fly bites an infected host, it also ingests macrophages infected by rounded and nonmotile amastigote forms. Then, the parasites transform from the amastigote to the flagellate promastigote stage, multiply by binary fission in the midgut, and migrate to the foregut and in mouth parts (pharynx, cibarium, and proboscis) of the infected sand fly vector. Subsequently, it can be transmitted to other new hosts, where these flies feed on blood meals, and the invertebrate cycle is concluded. When the infectious promastigote forms are inoculated from the vector's proboscis into the host's skin, they are phagocytized by macrophages. They then evolve into the amastigote form, where reproducing asexually and continuously in macrophages until rupture occurs. The parasites spread by invading mononuclear phagocytes in many organs, mostly spleen, liver, bone marrow, lymph node, and other tissues [7, 42-47].

Intriguingly, the occurrence of autochthonous cases of VL in places where the presence of phlebotomine has not been proven suggests other routes of transmission. Although nonsand fly transmission is reputed to be low, several studies have clearly shown the potential impact of nontraditional transmission routes in CanL, particularly sexual (venereal) and transplacental (vertical) transmission, which may have epidemiological significance in the dissemination and maintenance of disease, especially in the absence of the biological insect vector [48].

Sexual and transplacental transmission of Leishmania has already been reported in mice [49], humans [50-54], and dogs [55-59]. Genital lesions associated with VL have been well documented in dogs [60-62] and it seems that sexual transmission in dogs tends to be more efficient from the infected male to a susceptible female [63]. Leishmania sp. was detected in many biological samples from stillborn or newborn puppies [64-66], symptomatic or asymptomatic naturally infected bitches [67], associated with necrotizing placentitis and abortion [68] or any gross or microscopic changes in the placenta [69]. Together these studies strongly support the notion that CanL is vertically transmitted. Other forms of transmission, such as infection during blood transfusion [70] or derivatives from infected donors [71, 72], organ transplantation $[73,74]$, and sharing of contaminated needles [75], should be carefully considered mostly in dog and human hosts. Additionally, a suspected mode of transmission is the direct dog-to-dog transmission of the parasite by wounds or dog bites [76, 77].

Other blood-feeding arthropods, such as ticks or fleas, have sometimes been suspected of transmitting Leishmania based on the association of CanL with the presence of these alternative vectors $[78,79]$. Despite there being no definitive conclusion about the role of these ectoparasites in the transmission cycle of the disease $[79,80]$, it is nonetheless advisable to prevent and treat dogs against fleas, ticks, and mosquitoes [81].

\section{Immunology and Clinical Signs}

The number and intensity of clinical signs are determined by a set of factors involving parasite strain, genetics, and the host immune status. In this way, some dogs are able to control the infection for many years, without the appearance of clinical signs, and sometimes may even evolve spontaneous cure. On the other hand, some infected dogs may display an acute evolution and severe disease, or progressive course that leads inexorably to death, if proper management and therapy are not adopted.

The clinical diagnosis of CanL is complex, since almost $50 \%$ of the affected canine population does not exhibit clinical signs [92]. Moreover, when dogs are ill, they manifest a variable and nonspecific clinical spectrum [34], because CanL is a chronic and multisystemic disease that may potentially involve any organ [91].

Clinical manifestations of dogs naturally infected with L. infantum are shown in Figure 1. Clinical signs may be 


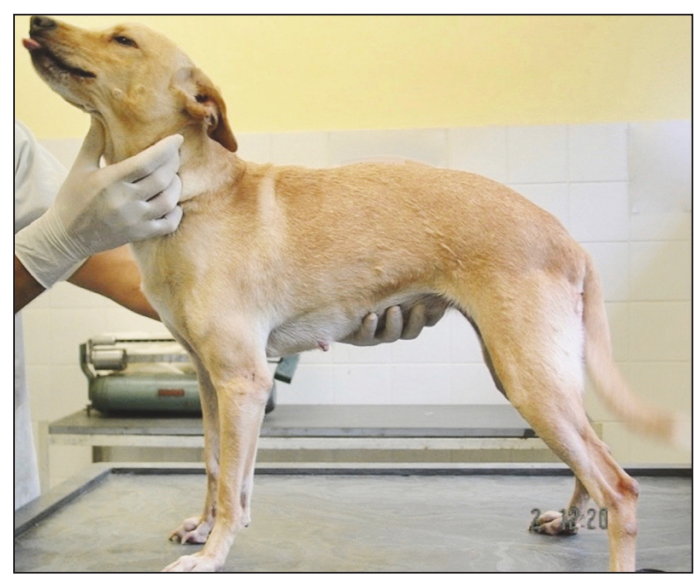

(a)

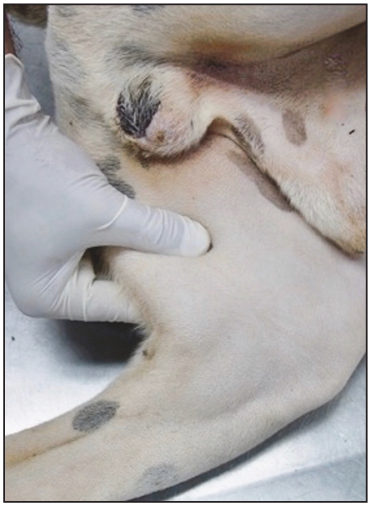

(c)

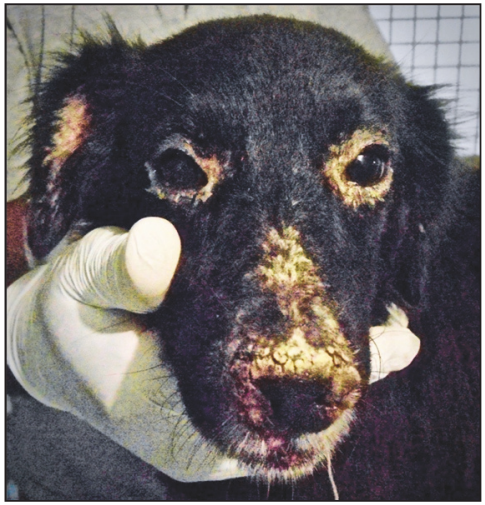

(d)

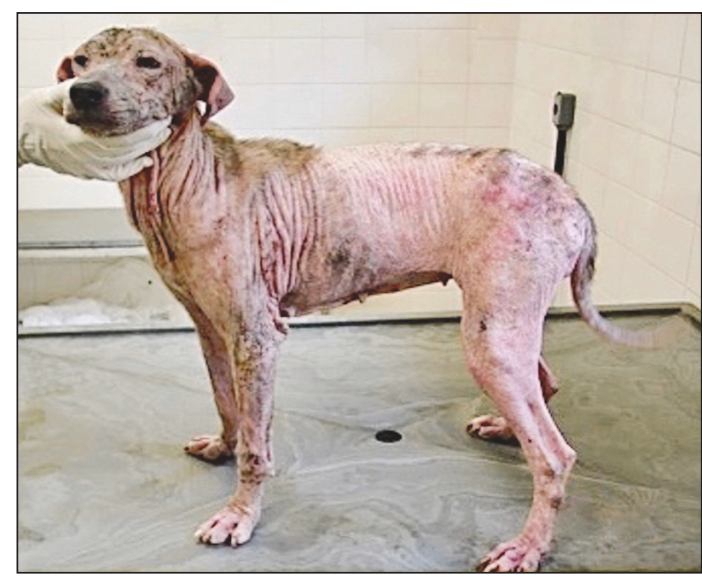

(b)

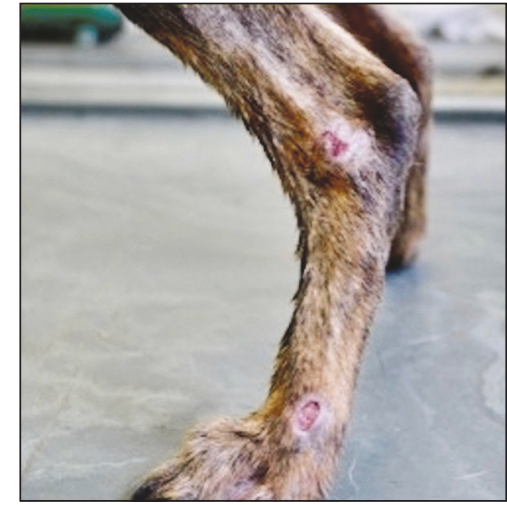

(e)

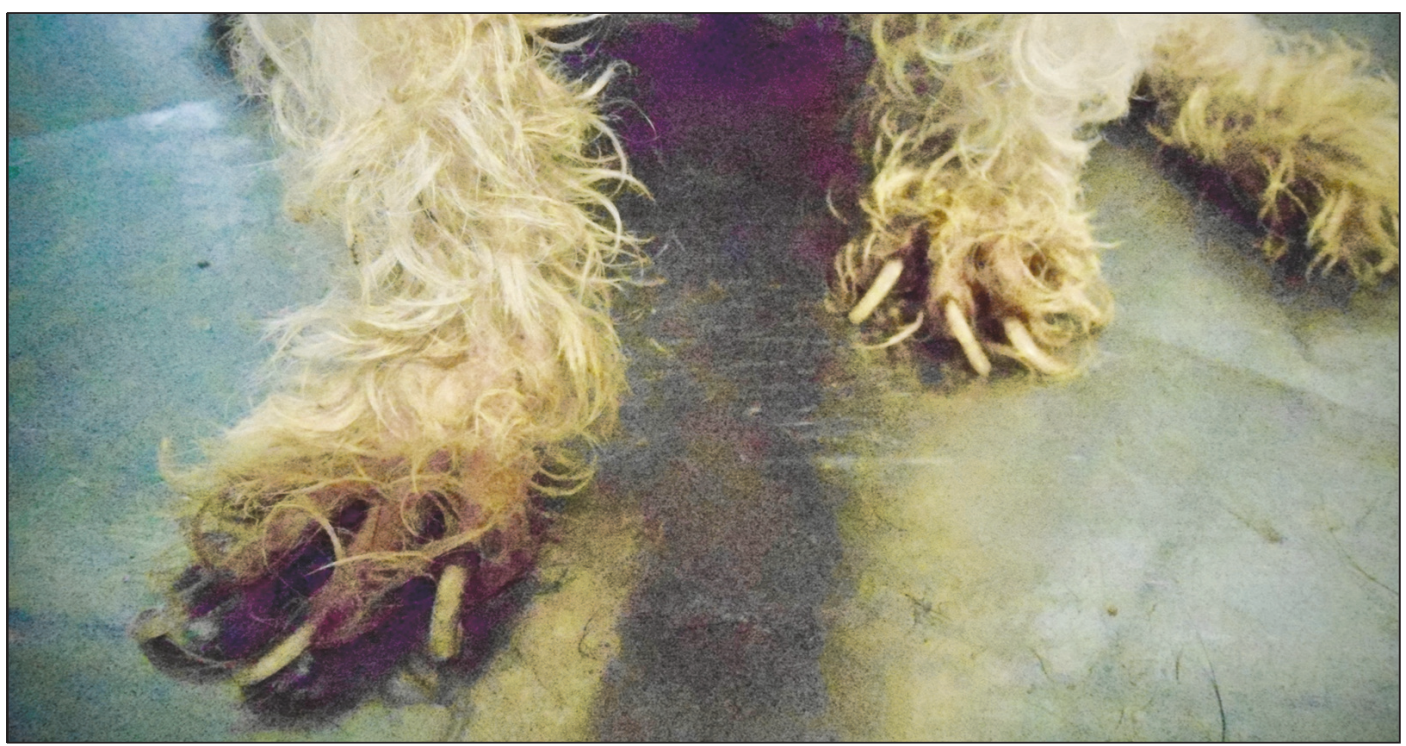

(f)

FIGURE 1: Clinical manifestations of dogs naturally infected with Leishmania (Leishmania) infantum: (a) asymptomatic dog (apparently healthy but infected); (b) generalized nonpruritic alopecia and multiple other dermatological abnormalities; (c) popliteal lymphadenomegaly; (d) bilateral blepharitis and extensive muzzle involvement with marked exfoliative ulcerative lesions; (e) ulcerative lesions at the bony prominences of the hind limb leg; (f) onychogryphosis. Photos by Raul Rio Ribeiro and Cristiano Cheim Peixoto dos Santos. 
present from three months to several years after dogs become infected [93]. In the classic cutaneovisceral form, one of the earliest and most common clinical signs of the disease is lymphadenopathy, mainly affecting the popliteal (Figure 1(c)), prescapular, and submaxillary lymph nodes [94]. Dermatological abnormalities occur later and are frequent and variable in their characterization and extension [95]. About $90 \%$ of these dogs present cutaneous lesions; however, dermatological alterations are rare in the absence of other signs of the disease [96]. The classic dermatological patterns include nonpruritic exfoliative dermatitis with or without alopecia, which can be localized or disseminated (Figures 1(b), 1(d)); erosive-ulcerative dermatitis (Figure 1(e)); nodular, papular, or pustular dermatitis; nasal hyperkeratosis (Figure 1(d)); nasal depigmentation and onychogryphosis (Figure 1(f)) [93, 97, 98]. Other signs involve anorexia, chronic enteritis and weight loss, splenomegaly and hepatomegaly, ophthalmopathy, and hypotrophy muscle [91, 93, 97, 99], as well as unusual or atypical signs like arthritis and neurological manifestations $[100,101]$.

Renal disease may be the sole clinical manifestation of CanL and it can progress from mild proteinuria to nephrotic syndrome or to an end stage renal disease [91]. Chronic renal failure is a severe result of disease progression and is the most common cause of death [91, 97].

There are two known clinical staging systems for CanL, with a good level of agreement between them [102], which contribute to the establishment of a more accurate diagnosis, prognosis, and treatment [103] by grouping the affected dogs according to the severity of their clinical presentation. In the LeishVet System, the disease is classified into four stages of evolution [Stage I: mild disease; Stage II: moderate disease (Substages A and B); Stage III: severe disease; Stage IV: very severe disease] based on physical examination and associated with the levels of antibodies determined by indirect immunofluorescence and biochemical-hematological findings [including detailed evaluation of renal function in conformity with International Renal Interest Society (IRIS)] [91]. The Canine Leishmaniasis Working Group (CLWG) System classifies dogs into five stages [Stage A: exposed dogs; Stage B: infected dogs; Stage C: sick dogs (dogs with clinically evident leishmaniasis); Stage D: severely sick dogs; Stage E: unresponsive to treatment or early relapse] according to clinical condition and associated with serological and parasitological (cytology, histology, or PCR) diagnosis and clinicopathological abnormalities [97, 104].

There remains no consensus on the exact relevance of each clinical form in the transmission cycle of the parasite. Some evidence suggests that the majority of transmission events to vectors result from a small proportion of infectious dogs with very high skin parasite loads, which would be correlated to severe disease $[105,106]$. On the other hand, asymptomatic dogs could be also highly infectious, indicating their role in maintaining and spreading the parasite in endemic areas [107]. Despite these contradictory results and until specific and sensitive markers of infectiousness, whether direct or indirect, are available, it is prudent to consider that both symptomatic and asymptomatic dogs could be infectious to sand fly vectors and that they should therefore be considered equally when proposing control measures.
The immune mechanisms responsible for resistance or susceptibility to infection are not yet well known. The effectiveness of the immune response is a fundamental aspect in the pathogenesis of the disease and its progression [108], playing a crucial role in clinical manifestations of CanL.

In humans [109], mice [110], and dogs [93, 111] the protective immunity against leishmaniasis is mediated by $\mathrm{T}$ cells and is associated with the production of IFN- $\gamma$ and TNF- $\alpha$, while the role of Th2 cytokines, such as IL- 4 and IL-10, and exuberant humoral response are related to progressive disease $[93,103,111,112]$.

It seems that the susceptibility to CanL of some breeds, such as Boxer, Cocker Spaniel, Rottweiler, and German Shepherd, can be associated with the expression of the Slcllal (Solute Carrier family 11a member 1; formerly NRAMP1) gene and/or major histocompatibility complex (MHC) class II polymorphism [113-116]. Conversely, the Ibizan Hound has been reported to be more resistant to Leishmania infection due to it displaying a predominantly cellular immune response $[113,117]$.

The greater rate of infection in working dog breeds is possibly due to more contact time with the insect vector in outside environments. Although controversial, the length of the coat can probably influence the risk of infection, since it is a characteristic that varies greatly among canine breeds. In short, it seems that the chances of acquiring Leishmania infection are lower in mixed-breed female dogs, with long hair, maintained in domestic-restricted or restrained (dogs raised indoors) without the presence of green surroundings close to home [118].

\section{Laboratory Findings}

The laboratory analysis of parameters related to hematopoiesis, renal function, and serum electrophoretic profile must be used in the clinical routine as a complementary tool in diagnosis. The marked polyclonal humoral response that occurs after infection gives rise to visible changes in the electrophoretic plasma profile and contributes to the occurrence of organs damage, such as kidneys, eyes, and skin. In addition, high parasite loads in the components of the mononuclear phagocyte system (MPS), for example, in bone marrow and liver, triggering the occurrence of clinical pathology related to hepatic and hematopoietic functions [34].

Anemia is one of the main laboratory findings on the hemogram. It is likely that more than one factor is involved in the etiology of anemia, such as hemorrhage, hemolysis, chronic renal failure, bone marrow hypoplasia, or aplasia, and decreased lipid fluidity of the erythrocyte membrane [34, $119,120]$. The fact that 50 to $70 \%$ of patients present normocytic/normochromic and nonregenerative anemia suggests, at the very least, the participation of chronic inflammatory disease and/or impairment of erythropoiesis due to infectioninduced changes in bone marrow and/or kidneys [34]. Apparently, there is a relationship between anemia and clinical forms of the disease $[34,121,122]$. Bone marrow dysfunction does not usually involve precursor cells of leukocytes $[34,121]$, although dermatological lesions accompanied by secondary bacterial infections, or other comorbidities, can do so. 
Dysproteinemia is considered one of the most important changes in the disease [34]. Protein imbalance is represented by the increase of total serum proteins (hyperproteinemia), hyperglobulinemia, and hypoalbuminemia, which also determines the inversion in the albumin/globulin ratio. Hyperglobulinemia is a result of the discrete or scarce increase of the $\alpha$ and $\beta$ fractions accompanied by a significant increase of the $\gamma$-globulins, determining the hypergammaglobulinemia. The reduction of albumin levels is partly a result of renal excretion due to glomerular damage produced during the course of the disease and the low production by the liver in cases of liver failure.

CanL is often characterized by an increase in total serum proteins (hyperproteinemia), azotemia, hypergammaglobulinemia (polyclonal B cell response), hypoalbuminemia (renal and/or liver failure) [123], and values of A-G ratio below the lower limit of reference [34], since it is recognized that kidney damage associated with the disease is almost inevitable [34], which reinforces the fact that these parameters are good markers for diagnosis and therapeutic monitoring.

Renal disease in CanL may manifest as mild proteinuria to nephrotic syndrome or chronic renal failure, in which there is glomerulonephritis usually associated with the deposition of immune complexes in the kidneys. The activity of hepatic enzymes is generally within the reference values for the canine species, although biochemical findings in infected dogs can include alterations in aspartate aminotransferase, alanine aminotransferase, and alkaline phosphatase [123, 124].

\section{Diagnosis}

To improve the prognosis and to avoid both human and dog transmission (from false negative cases) and unnecessary euthanasia (from false-positive cases), diagnosis should be established as soon as possible, even on the basis of only a few or even a single clinical sign [42]. The diagnosis is made considering the epidemiological origin and the set of clinical signs presented by the dog [91]. Due to the large number of asymptomatic dogs and the absence of pathognomonic clinical signs, the diagnosis depends on laboratory support. All the parasitological, immunological, and molecular techniques available for diagnosis are important and need to be interpreted according to their benefits and limitations.

Parasitological diagnosis is the unique definitive method, which is often based on observations of amastigotes, preferentially in lymphoid organs such as bone marrow, lymph nodes, and spleen, as well as the liver and skin. In the clinical routine, a fragment obtained by skin biopsy allows the preparation of slides for cytological and histopathological/immunohistochemical techniques [125]. The aspiration biopsy from lymph nodes, bone marrow, or spleen can be evaluated by smears stained by Giemsa or Panoptic methods and, more rarely, in culture media (NNN, LIT, and $\alpha$-MEM, among others). The sensitivity of the bone marrow smear is about $60-85 \%$ and $30-40 \%$ for lymph node [126]. According to the literature, splenic aspirates are considered as the method of choice for parasitological diagnosis in CanL [127].

Molecular techniques have high sensitivity and specificity, and PCR and qPCR are currently part of the veterinary diagnostic routine, which are especially useful for follow-up and may be performed on various biological samples, such as peripheral blood, bone marrow aspirate or lymph nodes, skin fragment, and others $[91,128,129]$. It is important to highlight that information provided by $\mathrm{PCR} / \mathrm{qPCR}$ should not be separated from the data obtained from clinicopathological and serological evaluations [91].

CanL is frequently diagnosed through the detection of specific antibodies against Leishmania sp., preferably using quantitative serological techniques like immunofluorescence antibody test (IFAT) and enzyme-linked immunosorbent assay (ELISA). However, serological tests present important limitations, such as cross-reactions with Trypanosoma parasites, cutaneous leishmaniasis species, and other hemoparasites $[130,131]$, as well as false negative results in anergy cases or low titers (dubious reactions) [132].

Recently, immunochromatographic assays have been employed as routine laboratory tests in veterinary clinics for the detection of dozens of diseases including CanL. These tests are quick and easy (about 15 minutes) to perform, require no trained personnel or specialized laboratory training to interpret the results, and present reliable indexes of sensitivity and specificity. For CanL, usually recombinant proteins of the parasite, like rK39, are impregnated onto nitrocellulose membranes, and serum samples are applied in the rapid test platform. The Brazilian Ministry of Health officially established a rapid chromatographic immunoassay for canine survey based on dual path platform (DPP $\left.{ }^{\circledR}\right)$ for disease screening and ELISA as a confirmatory test [133]. From the point of view of public health, positive results in serological tests are used as a criterion for indication of euthanasia in suspected dogs based on the elimination program for control of $\mathrm{VL}$ adopted in Brazil.

\section{Treatment}

Even though parasitological cures are rarely achieved, and clinical recurrences in CanL often occur after therapy, it is necessary to consider that the available protocols can promote clinical cure, increase the life expectancy, and improve the quality of life, in addition to reducing the parasite load and infectiousness to sand fly vectors. Thus, the decision to treat a diseased dog is the result of a discussion between the dog owner and the veterinarian. An important factor analyzed is the owner's ability and/or willingness to comply with the treatment protocol [42], in addition to the assessment of the dog's potential responsiveness to therapy by a complete serologic, hematologic, and biochemical profile and urine analysis in order to evaluate, principally, the bone marrow and renal and hepatic status. According to the literature, the clinical response to treatment can vary from poor to good depending on their overall initial clinicopathological status and their specific response to therapy. For instance, dogs with renal insufficiency are expected to have a lower recovery rate in comparison to those without compromised kidneys or only mild proteinuria [91]. For reasons of public health and to prevent reinfection, the constant use of permethrin spoton and/or flumethrin or deltamethrin-impregnated collars in treated dogs and continuous veterinary monitoring is necessary. 
Current treatment protocols are summarized in Table 1. Some chemotherapeutic compounds used in the treatment of CanL are included within the 19th edition of World Health Organization (WHO) Model List of Essential Medicines against leishmaniasis: pentavalent antimonials $\left(\mathrm{Sb}^{\mathrm{v}}\right)$, miltefosine, amphotericin B deoxycholate or formulated in liposomal formulations, and paromomycin [43]. In addition to the drugs mentioned, there are other products that are proposed to modulate the immune response, immunostimulating the animal organism, such as domperidone, cytokines, and vaccines (immunotherapy). However, in veterinary medicine, allopurinol (a purine analog) is considered the major first line drug for long-term treatment of CanL, often in combination with pentavalent antimonials or miltefosine for the first month and then continued alone $[91,134]$. While it is rarely used for the treatment of human leishmaniasis, as allopurinol is the only drug recommended by the $\mathrm{WHO}$ for the treatment of CanL, recently the first report of resistance to allopurinol was published in L. infantum parasites isolated from dogs, and this was associated with clinical relapse [135]

Treatment of CanL with miltefosine (Milteforan ${ }^{\circledR}$ ) was authorized in Brazil in 2017, a decade after its introduction in Southern Europe. However, after a six-year follow-up, clinical and laboratory findings indicated that meglumine antimoniate plus allopurinol had better clinical efficacy than miltefosine plus allopurinol in CanL [134].

The most frequently chosen treatment for CanL is antimoniate meglumine (pentavalent antimonial) administered subcutaneously at the dose of $100 \mathrm{mg} / \mathrm{kg}$ once a day for 1 month together with allopurinol (leishmaniostatical drug) administered orally $10 \mathrm{mg} / \mathrm{kg}$ every 12 hours for six months minimum [91, 134, 136] (Table 1). The duration of the treatment depends on the severity of the disease, individual tolerance of drugs, and clinical response to treatment. There are also several side effects, such as xanthinuria, renal mineralisation, and urolithiasis in the case of long-term treatment with allopurinol, and meglumine antimoniate can be potentially nephrotoxic and miltefosine can produce gastrointestinal upset $[91,129,137]$.

Some immunomodulator-based treatments, like domperidone, can enhance innate defense mechanisms, activating phagocytic cells and potentiating the intracellular killing of the parasites, which can help to prevent CanL and reduce the risk of developing the clinical disease [138]. Recently, a study unprecedentedly registered the parasitological cure of dogs with VL treated with an innovative combined therapy with liposome-encapsulated meglumine antimoniate and allopurinol [139].

Knowledge about host-parasite relationships in dogs is increasing and signals the existence of factors inherent to the host, such as immunological differences in response to infection, which would influence the efficacy of the treatment. With this in mind, research groups seek the cure of dogs through new formulations of existing drugs or by associating them with immunostimulants and immunotherapeutics. The observed results indicate improved treatment in the future.

\section{Prevention and Control}

Considering that the sand fly bite is the most important route of transmission of CanL, the infection control measures should be primarily focused on preventing contact with the insect vector, either through physical barriers (fine mesh nets in windows and kennels), chemical barriers (repellents), or handling (avoiding exposure to twilight, eliminating organic peridomiciliary material). Predicting a large possibility of failure of these measures, the dog still needs to be able to respond to the infection challenge caused by the bites of infected sand flies, preferentially by an adaptive immune response previously developed through vaccination, or as a last alternative, by chemotherapeutics, which can boost the immune system to help fight infection.

Current prophylactic measures used for the prevention and control of CanL are summarized in Table 1. Repellent products available for preventing CanL contain synthetic pyrethroids (deltamethrin, permethrin, or flumethrin) alone or in combination with other insecticides, which displays a synergistic effect on insects. The protection effect against sand flies after use may range from 2-4 weeks in spot-on formulations to 4-8 months in impregnated PVC collars (Scalibor ${ }^{\circledR}$ and Seresto $\left.{ }^{\circledR}\right)$, which must be used in both noninfected and infected dogs [140-143].

Vaccination against CanL is a recent tool for pet owners and unfortunately the two commercial vaccines available have low protective efficacy of about $68-71 \%$ (Canileish ${ }^{\circledR}$ 68.4\%; Leish-Tec $\left.{ }^{\circledR} 71 \%\right)[82,84,144]$.

There is no scientific evidence that seropositive dog culling could reduce the incidence of VL $[145,146]$, and wherever this has been applied (e.g., Brazil and Balkan and Central Asian countries), national programs for VL control have failed. Therefore, vaccination against Leishmania associated with topical insecticides is undoubtedly the most effective form of prevention and control of CanL.

\section{Conclusions}

CanL is a zoonotic chronic disease transmitted mostly by infected sand flies and can be potentially fatal to humans and dogs. Their epidemiological, clinical, and laboratory aspects are very variable, which makes it difficult for veterinary practitioners to complete a diagnosis and then treat and control the disease, especially due to the lack of more effective drugs and vaccines. However, considerable efforts are being made by professionals from multidisciplinary areas in order to improve the knowledge about this parasitic disease, so that prevention, treatment and control may be improved in the future.

\section{Conflicts of Interest}

The authors declare that there are no conflicts of interest regarding the publication of this article.

\section{Acknowledgments}

The authors gratefully acknowledge FAPEMIG (Research Support Foundation of Minas Gerais) for its financial support. 


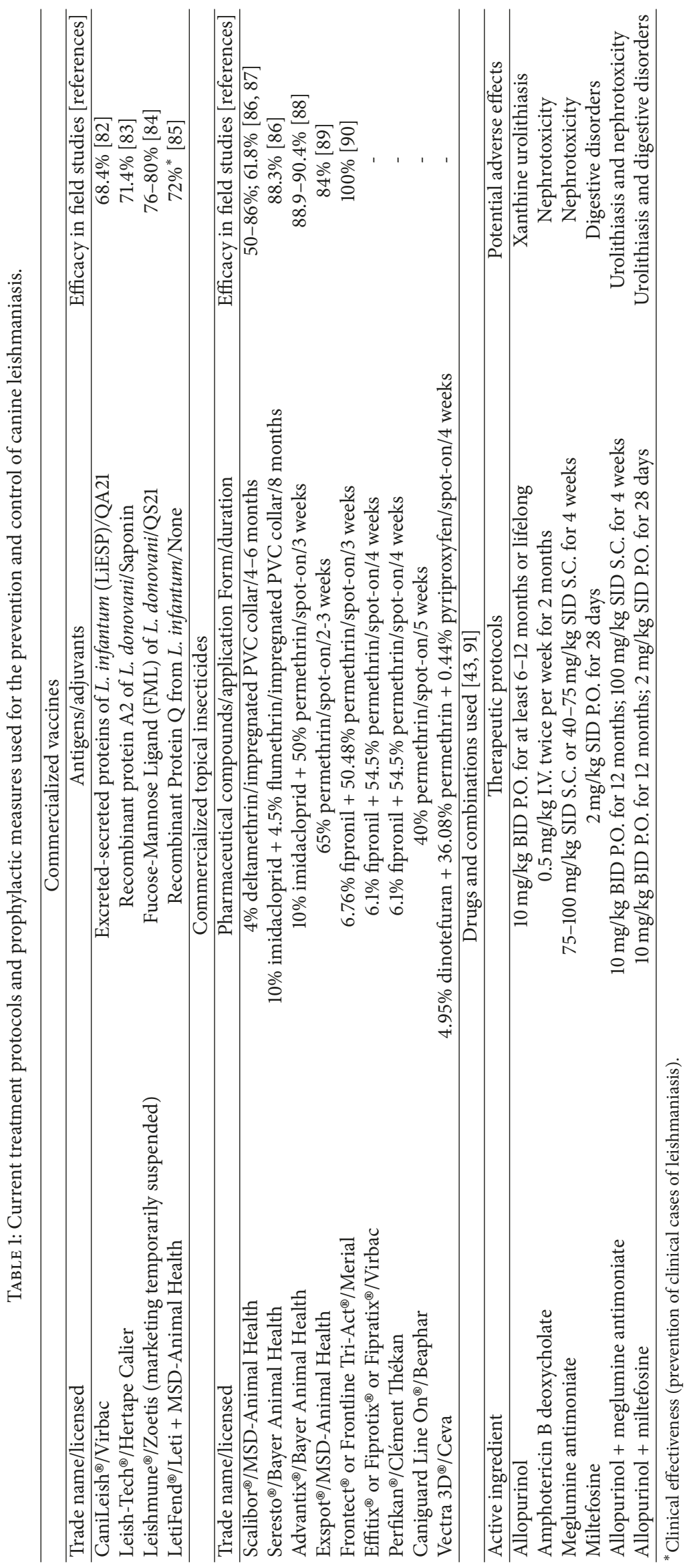




\section{References}

[1] World Health Organization, "Control of the leishmaniasis," Report of the meeting of the WHO Expert Committee on the Control of Leishmaniases, Geneva, Switzerland, 2010, Vol. 9492010.

[2] J. Alvar, I. D. Vélez, C. Bern et al., "Leishmaniasis worldwide and global estimates of its incidence," PLoS ONE, vol. 7, no. 5, Article ID e35671, 2012.

[3] E. T. Caldart, R. L. Freire, F. P. Ferreira et al., "Leishmania in synanthropic rodents (Rattus rattus): New evidence for the urbanization of Leishmania (Leishmania) amazonensis," Revista Brasileira de Parasitologia Veterinária, vol. 26, no. 1, pp. 17-27, 2017.

[4] K. Tsakmakidis and C. I. Dovas, "Leishmania infection in rodents in Greece," in Proceedings of the I. Tsakmakidis, vol. 22, pp. 1523-1532, 2017.

[5] E. K. Saliba and O. Y. Oumeish, "Reservoir hosts of cutaneous leishmaniasis," Clinics in Dermatology, vol. 17, no. 3, pp. 275-277, 1999.

[6] N. H. De Almeida Curi, I. Miranda, and S. A. Talamoni, "Serologic evidence of Leishmania infection in free-ranging wild and domestic canids around a Brazilian National Park," Memórias do Instituto Oswaldo Cruz, vol. 101, no. 1, pp. 99-101, 2006.

[7] F. Dantas-Torres, "The role of dogs as reservoirs of Leishmania parasites, with emphasis on Leishmania (Leishmania) infantum and Leishmania (Viannia) braziliensis," Veterinary Parasitology, vol. 149, no. 3-4, pp. 139-146, 2007.

[8] F. B. Figueiredo, I. D. F. Gremião, S. A. Pereira et al., "First report of natural infection of a bush dog (Speothos venaticus) with Leishmania (Leishmania) chagasi in Brazil," Transactions of the Royal Society of Tropical Medicine and Hygiene, vol. 102, no. 2, pp. 200-201, 2008.

[9] N. P. Souza, A. D. B. P. F. de Almeida, T. P. T. de Freitas et al., "Leishmania (Leishmania) infantum chagasi in wild canids kept in captivity in the State of Mato Grosso," Journal of the Brazilian Society of Tropical Medicine, vol. 43, no. 3, pp. 333-335, 2010.

[10] A. L. R. Roque and A. M. Jansen, "Wild and synanthropic reservoirs of Leishmania species in the Americas," International Journal for Parasitology: Parasites and Wildlife, vol. 3, no. 3, pp. 251262, 2014.

[11] R. Lainson, R. R. Braga, A. A. De Souza, M. M. Pôvoa, E. A. Ishikawa, and F. T. Silveira, "Leishmania (Viannia) shawi sp. n., a parasite of monkeys, sloths and procyonids in Amazonian Brazil," Annales de Parasitologie Humaine Et Comparée, vol. 64, no. 3, pp. 200-207, 1989.

[12] V. A. L. De Araújo, M. C. Boité, E. Cupolillo, A. M. Jansen, and A. L. R. Roque, "Mixed infection in the anteater Tamandua tetradactyla (Mammalia: Pilosa) from Pará State, Brazil: Trypanosoma cruzi, T. rangeli and Leishmania infantum," Parasitology, vol. 140, no. 4, pp. 455-460, 2013.

[13] D. Talmi-Frank, C. L. Jaffe, A. Nasereddin et al., "Leishmania tropica in rock hyraxes (Procavia capensis) in a focus of human cutaneous leishmaniasis," The American Journal of Tropical Medicine and Hygiene, vol. 82, no. 5, pp. 814-818, 2010.

[14] A. Montoya, L. P. De Quadros, M. Mateo et al., "Leishmania infantum infection in Bennett's Wallabies (Macropus rufogriseus rufogriseus) in a Spanish wildlife park," Journal of Zoo and Wildlife Medicine, vol. 47, no. 2, pp. 586-593, 2016.

[15] H. De Lima, N. Rodríguez, M. A. Barrios, Á. Ávila, I. Cañizales, and S. Gutiérrez, "Isolation and molecular identification of
Leishmania chagasi from a bat (Carollia perspicillata) in northeastern Venezuela," Memórias do Instituto Oswaldo Cruz, vol. 103, no. 4, pp. 412-414, 2008.

[16] E. de Castro Ferreira, A. A. S. Pereira, M. Silveira et al., "Leishmania (V.) braziliensis infecting bats from Pantanal wetland, Brazil: First records for Platyrrhinus lineatus and Artibeus planirostris," Acta Tropica, vol. 172, pp. 217-222, 2017.

[17] M. B. Rezende, H. M. Herrera, and C. M. E. Carvalho, "Detection of in bats from an area of Brazil endemic for visceral leishmaniasis," Transboundary and Emerging Diseases, vol. 64, no. 6, 2017.

[18] R. Molina, M. I. Jiménez, I. Cruz et al., "The hare (Lepus granatensis) as potential sylvatic reservoir of Leishmania infantum in Spain," Veterinary Parasitology, vol. 190, no. 1-2, pp. 268271, 2012

[19] N. García, I. Moreno, J. Alvarez et al., "Evidence of Leishmania infantum infection in rabbits (Oryctolagus cuniculus) in a natural area in Madrid, Spain," BioMed Research International, vol. 2014, Article ID 318254, 2014.

[20] M. Jiménez, E. González, I. Martín-Martín, S. Hernández, and R. Molina, "Could wild rabbits (Oryctolagus cuniculus) be reservoirs for Leishmania infantum in the focus of Madrid, Spain?" Veterinary Parasitology, vol. 202, no. 3-4, pp. 296-300, 2014.

[21] C. N. Tsokana, C. Sokos, A. Giannakopoulos et al., "First evidence of Leishmania infection in European brown hare (Lepus europaeus) in Greece: GIS analysis and phylogenetic position within the Leishmania spp," Parasitology Research, vol. 115, no. 1, pp. 313-321, 2016.

[22] R. Lainson, "The Neotropical Leishmania species: a brief historical review of their discovery, ecology and taxonomy," Revista Pan-Amazônica de Saúde, vol. 1, no. 2, 2010.

[23] M. Maroli, M. G. Pennisi, T. Di Muccio, C. Khoury, L. Gradoni, and M. Gramiccia, "Infection of sandflies by a cat naturally infected with Leishmania infantum," Veterinary Parasitology, vol. 145, no. 3-4, pp. 357-360, 2007.

[24] S. M. da Silva, P. F. B. Rabelo, N. D. F. Gontijo et al., "First report of infection of Lutzomyia longipalpis by Leishmania (Leishmania) infantum from a naturally infected cat of Brazil," Veterinary Parasitology, vol. 174, no. 1-2, pp. 150-154, 2010.

[25] M. A. A. Dahroug, A. B. P. F. Almeida, V. R. F. Sousa et al., "Leishmania (Leishmania) chagasi in captive wild felids in Brazil," Transactions of the Royal Society of Tropical Medicine and Hygiene, vol. 104, no. 1, pp. 73-74, 2010.

[26] M. A. Dahroug, A. B. Almeida, V. R. Sousa et al., "The first case report of Leishmania (leishmania) chagasi in Panthera leo in Brazil," Asian Pacific Journal of Tropical Biomedicine, vol. 1, no. 3, pp. 249-250, 2011.

[27] C. M. Aguilar, E. F. Rangel, L. Garcia et al., "Zoonotic cutaneous leishmaniasis due to Leishmania (Viannia) braziliensis associated with domestic animals in Venezuela and Brazil," Memórias do Instituto Oswaldo Cruz, vol. 84, no. 1, pp. 19-28, 1989.

[28] I. R. Soares, S. O. Silva, F. M. Moreira et al., "First evidence of autochthonous cases of Leishmania (Leishmania) infantum in horse (Equus caballus) in the Americas and mixed infection of Leishmania infantum and Leishmania (Viannia) braziliensis," Veterinary Parasitology, vol. 197, no. 3-4, pp. 665-669, 2013.

[29] M. C. C. Malta, H. P. Tinoco, M. N. Xavier, A. L. S. Vieira, É. A. Costa, and R. L. Santos, "Naturally acquired visceral leishmaniasis in non-human primates in Brazil," Veterinary Parasitology, vol. 169, no. 1-2, pp. 193-197, 2010. 
[30] E. Dumonteil, R.-S. M. Jesus, E.-O. Javier, and G.-M. M. Del Rosario, "DNA vaccines induce partial protection against Leishmania mexicana," Vaccine, vol. 21, no. 17-18, pp. 2170-2177, 2003.

[31] C. H. N. Costa, "How effective is dog culling in controlling zoonotic visceral leishmaniasis? A critical evaluation of the science, politics and ethics behind this public health policy," Journal of the Brazilian Society of Tropical Medicine, vol. 44, no. 2, pp. 232242, 2011.

[32] M. Gramiccia and L. Gradoni, "The current status of zoonotic leishmaniases and approaches to disease control," International Journal for Parasitology, vol. 35, no. 11-12, pp. 1169-1180, 2005.

[33] C. Nicolle and C. Comte, "Origine canine du Kala-azar," Bulletin de la Société de Pathologie Exotique, vol. 1, pp. 299-301, 1908.

[34] R. R. Ribeiro, S. M. Silva, G. d. Fulgêncio, M. S. Michalick, and F. J. Frézard, "Relationship between clinical and pathological signs and severity of canine leishmaniasis," Revista Brasileira de Parasitologia Veterinária, vol. 22, no. 3, pp. 373-378, 2013.

[35] R. Lainson, J. J. Shaw, F. T. Silveira, and R. R. Braga, "American visceral leishmaniasis: on the origin of Leishmania (Leishmania) chagasi," Transactions of the Royal Society of Tropical Medicine and Hygiene, vol. 81, no. 3, p. 517, 1987.

[36] O. Courtenay, R. J. Quinnell, L. M. Garcez, and C. Dye, "Low infectiousness of a wildlife host of Leishmania infantum: The crab-eating fox is not important for transmission," Parasitology, vol. 125, no. 5, pp. 407-414, 2002.

[37] M. M. Luppi, M. C. C. Malta, T. M. A. Silva et al., "Visceral leishmaniasis in captive wild canids in Brazil," Veterinary Parasitology, vol. 155, no. 1-2, pp. 146-151, 2008.

[38] J. P. S. Mol, S. A. Soave, A. P. Turchetti et al., "Transmissibility of Leishmania infantum from maned wolves (Chrysocyon brachyurus) and bush dogs (Speothos venaticus) to Lutzomyia longipalpis," Veterinary Parasitology, vol. 212, no. 3-4, pp. 86-91, 2015.

[39] C. Maia and L. Campino, "Can domestic cats be considered reservoir hosts of zoonotic leishmaniasis?" Trends in Parasitology, vol. 27, no. 8, pp. 341-344, 2011.

[40] L. Solano-Gallego, A. Rodríguez-Cortés, L. Iniesta et al., "Cross-sectional serosurvey of feline leishmaniasis in ecoregions around the Northwestern Mediterranean," The American Journal of Tropical Medicine and Hygiene, vol. 76, no. 4, pp. 676680, 2007.

[41] M. Maroli, M. D. Feliciangeli, L. Bichaud, R. N. Charrel, and L. Gradoni, "Phlebotomine sand flies and the spreading of leishmaniases and other diseases of public health concern," Medical and Veterinary Entomology, vol. 27, no. 2, pp. 123-147, 2013.

[42] M. Gharbi, M. Mhadhbi, A. Rejeb, K. Jaouadi, M. Rouatbi, and M. A. Darghouth, "Leishmaniosis (Leishmania infantum infection) in dogs," Revue Scientifique et Technique de l'OIE, vol. 34, no. 2, pp. 613-626, 2015.

[43] R. M. Reguera, M. Morán, Y. Pérez-Pertejo, C. García-Estrada, and R. Balaña-Fouce, "Current status on prevention and treatment of canine leishmaniasis," Veterinary Parasitology, vol. 227, pp. 98-114, 2016.

[44] P. A. Bates, "Transmission of Leishmania metacyclic promastigotes by phlebotomine sand flies," International Journal for Parasitology, vol. 37, no. 10, pp. 1097-1106, 2007.

[45] A. Dostálová and P. Volf, "Leishmania development in sand flies: Parasite-vector interactions overview," Parasites \& Vectors, vol. 5, no. 1, article no. 276, 2012.

[46] I. Kaszak, M. Planellas, and B. Dworecka-Kaszak, "Canine leishmaniosis-an emerging disease," Annals of Parasitology, vol. 61, no. 2, pp. 69-76, 2015.
[47] A. Ayele and Z. Seyoum, "Review on canine leishmaniasis, etiology, clinical sign, pathogenesis, treatment and control methods," Global Veterinaria, vol. 17, no. 4, pp. 343-352, 2016.

[48] V. Svobodova, M. Svoboda, L. Friedlaenderova, P. Drahotsky, E. Bohacova, and G. Baneth, "Canine leishmaniosis in three consecutive generations of dogs in Czech Republic," Veterinary Parasitology, vol. 237, pp. 122-124, 2017.

[49] A. C. Rosypal and D. S. Lindsay, "Non-sand fly transmission of a North American isolate of Leishmania infantum in experimentally infected BALB/c mice," Journal of Parasitology, vol. 91, no. 5, pp. 1113-1115, 2005.

[50] W. S. Symmers, "Leishmaniasis acquired by contagion: a case of marital infection in Britain," The Lancet, vol. 1, pp. 127-132, 1960.

[51] C. K. Meinecke, J. Schottelius, L. Oskam, and B. Fleischer, "Congenital transmission of visceral leishmaniasis (Kala Azar) from an asymptomatic mother to her child.", Pediatrics, vol. 104, no. 5, p. e65, 1999.

[52] P. Pagliano, N. Carannante, M. Rossi et al., "Visceral leishmaniasis in pregnancy: A case series and a systematic review of the literature," Journal of Antimicrobial Chemotherapy, vol. 55, no. 2, pp. 229-233, 2005.

[53] C. C. Boehme, U. Hain, A. Novosel, S. Eichenlaub, E. Fleischmann, and T. Löscher, "Congenital visceral Leishmaniasis," Emerging Infectious Diseases, vol. 12, no. 2, pp. 359-360, 2006.

[54] A. Zinchuk and A. Nadraga, "Congenital visceral leishmaniasis in Ukraine: Case report," Annals of Tropical Paediatrics, vol. 30, no. 2, pp. 161-164, 2010.

[55] C. Riera and J. E. Valladares, "Viable Leishmania infantum in urine and semen in experimentally infected dogs," Parasitology Today, vol. 12, no. 10, p. 412, 1996.

[56] A. C. Rosypal, G. C. Troy, A. M. Zajac, G. Frank, and D. S. Lindsay, "Transplacental transmission of a North American isolate of Leishmania infantum in an experimentally infected beagle," Journal of Parasitology, vol. 91, no. 4, pp. 970-972, 2005.

[57] F. L. Silva, R. G. Oliveira, T. M. A. Silva, M. N. Xavier, E. F. Nascimento, and R. L. Santos, "Venereal transmission of canine visceral leishmaniasis," Veterinary Parasitology, vol. 160, no. 1-2, pp. 55-59, 2009.

[58] T. J. Naucke and S. Lorentz, "First report of venereal and vertical transmission of canine leishmaniosis from naturally infected dogs in Germany," Parasites \& Vectors, vol. 5, no. 1, article no. 67, 2012.

[59] T. Ben Slimane, E. Chouihi, S. Ben Hadj Ahmed et al., "An investigation on vertical transmission of Leishmania infantum in experimentally infected dogs and assessment of offspring's infectiousness potential by xenodiagnosis," Veterinary Parasitology, vol. 206, no. 3-4, pp. 282-286, 2014.

[60] F. L. Silva, A. A. M. Rodrigues, I. O. P. Rego et al., "Genital lesions and distribution of amastigotes in bitches naturally infected with Leishmania chagasi," Veterinary Parasitology, vol. 151, no. 1, pp. 86-90, 2008.

[61] C. G. Carvalho Junior, R. G. Teixeira Neto, V. V. Lopes et al., "Parasitism and inflammation in ear skin and in genital tissues of symptomatic and asymptomatic male dogs with visceral leishmaniasis," Parasitology Research, vol. 116, no. 3, pp. 987995, 2017.

[62] S. A. Diniz, M. S. Melo, A. M. Borges et al., "Genital lesions associated with visceral leishmaniasis and shedding of Leishmania sp. in the semen of naturally infected dogs," Veterinary Pathology, vol. 42, no. 5, pp. 650-658, 2005. 
[63] A. P. Turchetti, T. D. Souza, T. A. Paixão, and R. L. Santos, "Sexual and vertical transmission of visceral leishmaniasis," The Journal of Infection in Developing Countries, vol. 8, no. 4, pp. 403-407, 2014.

[64] K. N. Gibson-Corley, J. M. Hostetter, S. J. Hostetter et al., "Disseminated Leishmania infantum infection in two sibling foxhounds due to possible vertical transmission," Canadian Veterinary Journal, vol. 49, no. 10, pp. 1005-1008, 2008.

[65] K. S. Freeman, M. D. Miller, E. B. Breitschwerdt, and M. R. Lappin, "Leishmaniasis in a dog native to Colorado," Journal of the American Veterinary Medical Association, vol. 237, no. 11, pp. 1288-1291, 2010.

[66] P. M. Boggiatto, K. N. Gibson-Corley, K. Metz et al., "Transplacental transmission of Leishmania infantum as a means for continued disease incidence in North America," PLOS Neglected Tropical Diseases, vol. 5, no. 4, Article ID e1019, 2011.

[67] M. Masucci, M. De Majo, R. B. Contarino, G. Borruto, F. Vitale, and M. G. Pennisi, "Canine leishmaniasis in the newborn puppy," Veterinary Research Communications, vol. 27, no. 1, pp. 771-774, 2003.

[68] J. P. Dubey, A. C. Rosypal, V. Pierce, S. N. Scheinberg, and D. S. Lindsay, "Placentitis associated with leishmaniasis in a dog," Journal of the American Veterinary Medical Association, vol. 227, no. 8, pp. 1250-1269, 2005.

[69] K. K. Pangrazio, E. A. Costa, S. P. Amarilla et al., "Tissue distribution of Leishmania chagasi and lesions in transplacentally infected fetuses from symptomatic and asymptomatic naturally infected bitches," Veterinary Parasitology, vol. 165, no. 3-4, pp. 327-331, 2009.

[70] S. D. Owens, D. A. Oakley, K. Marryott et al., "Transmission of visceral leishmaniasis through blood transfusions from infected English Foxhounds to anemic dogs," Journal of the American Veterinary Medical Association, vol. 219, no. 8, pp. 1076-1083, 2001.

[71] E. De Freitas, M. N. Melo, A. P. Da Costa-Val, and M. S. M. Michalick, "Transmission of Leishmania infantum via blood transfusion in dogs: potential for infection and importance of clinical factors," Veterinary Parasitology, vol. 137, no. 1-2, pp. 159$167,2006$.

[72] M. D. Tabar, X. Roura, O. Francinoy, L. Altety, and R. R. De Gopegui, "Detection of Leishmania infantum by real-time PCR in a canine blood bank," Journal of Small Animal Practice, vol. 49, no. 7, pp. 325-328, 2008.

[73] D. D. F. Ma, A. J. Concannon, and J. Hayes, "Fatal Leishmaniasis in renal-transplant patient," The Lancet, vol. 314, no. 8137, pp. 311312, 1979.

[74] S. Antinori, A. Cascio, C. Parravicini, R. Bianchi, and M. Corbellino, "Leishmaniasis among organ transplant recipients," The Lancet Infectious Diseases, vol. 8, no. 3, pp. 191-199, 2008.

[75] F. Morillas-Marquez, J. Martin-Sanchez, C. Acedo-Sanchez, J. A. Pineda, J. Macias, and J. Sanjuan-Garcia, "Leishmania infantum (Protozoa, Kinetoplastida): Transmission from infected patients to experimental animal under conditions that simulate needle-sharing," Experimental Parasitology emphasizes, vol. 100, no. 1, pp. 71-74, 2002.

[76] V. Karkamo, A. Kaistinen, A. Näreaho et al., "The first report of autochthonous non-vector-borne transmission of canine leishmaniosis in the Nordic countries," Acta Veterinaria Scandinavica, vol. 56, p. 84, 2014.

[77] T. J. Naucke, S. Amelung, and S. Lorentz, "First report of transmission of canine leishmaniosis through bite wounds from a naturally infected dog in Germany," Parasites \& Vectors, vol. 9, no. 1, article no. 256, 2016.

[78] G. F. Paz, M. F. B. Ribeiro, D. F. de Magalhães et al., "Association between the prevalence of infestation by Rhipicephalus sanguineus and Ctenocephalides felis felis and the presence of anti-Leishmania antibodies: A case-control study in dogs from a Brazilian endemic area," Preventive Veterinary Medicine, vol. 97, no. 2, pp. 131-133, 2010.

[79] V. V. G. de Oliveira, L. C. Alves, and V. A. da Silva, "Transmission routes of visceral leishmaniasis in mammals," Ciência Rural, vol. 45, no. 9, pp. 1622-1628, 2015.

[80] G. Baneth, “Tick-borne infections of animals and humans: A common ground," International Journal for Parasitology, vol. 44, no. 9, pp. 591-596, 2014.

[81] M. Franc, C. Genchi, E. Bouhsira et al., "Efficacy of dinotefuran, permethrin and pyriproxyfen combination spot-on against Aedes aegypti mosquitoes on dogs," Veterinary Parasitology, vol. 189, no. 2-4, pp. 333-337, 2012.

[82] G. Oliva, J. Nieto, V. Foglia Manzillo et al., "A randomised, double-blind, controlled efficacy trial of the liesp/qa-21 vaccine in naive dogs exposed to two Leishmania infantum transmission seasons," PLOS Neglected Tropical Diseases, vol. 8, no. 10, 2014.

[83] S. Regina-Silva, A. M. L. T. Feres, J. C. França-Silva et al., "Field randomized trial to evaluate the efficacy of the Leish-Tec ${ }^{\circledR}$ vaccine against canine visceral leishmaniasis in an endemic area of Brazil," Vaccine, vol. 34, no. 19, pp. 2233-2239, 2016.

[84] C. B. Palatnik-de-Sousa, "Vaccines for canine leishmaniasis," Frontiers in Immunology, vol. 3, article 69, 2012.

[85] "Committee for Medicinal Products for Veterinary Use (CVMP) European Public Assessment Report (EPAR) for LETIFEND,” European Medicines Agency, 2016.

[86] E. Brianti, E. Napoli, G. Gaglio et al., "Field evaluation of two different treatment approaches and their ability to control fleas and prevent canine leishmaniosis in a highly endemic area," PLOS Neglected Tropical Diseases, vol. 10, no. 9, Article ID e0004987, 2016.

[87] M. Maroli, V. Mizzoni, C. Siragusa, A. D’Orazi, and L. Gradoni, "Evidence for an impact on the incidence of canine leishmaniasis by the mass use of deltamethrin-impregnated dog collars in southern Italy," Medical and Veterinary Entomology, vol. 15, no. 4, pp. 358-363, 2001.

[88] D. Otranto, P. Paradies, R. P. Lia et al., "Efficacy of a combination of $10 \%$ imidacloprid $/ 50 \%$ permethrin for the prevention of leishmaniasis in kennelled dogs in an endemic area," Veterinary Parasitology, vol. 144, no. 3-4, pp. 270-278, 2007.

[89] E. Ferroglio, M. Poggi, and A. Trisciuoglio, "Evaluation of $65 \%$ permethrin spot-on and deltamethrin-impregnated collars for canine Leishmania infantum infection prevention," Zoonoses and Public Health, vol. 55, no. 3, pp. 145-148, 2008.

[90] E. Papadopoulos, A. Angelou, A. Diakou, L. Halos, and F. Beugnet, "Five-month serological monitoring to assess the effectiveness of permethrin/fipronil (Frontline Tri-Act ${ }^{\circledR}$ ) spoton in reducing the transmission of Leishmania infantum in dogs," Veterinary Parasitology: Regional Studies and Reports, vol. 7, pp. 48-53, 2017.

[91] L. Solano-Gallego, G. Miró, A. F. Koutinas et al., "LeishVet guidelines for the practical management of canine leishmaniasis," Parasites \& Vectors, vol. 4, article 86, 2011.

[92] F. Mancianti, M. Gramiccia, L. Gradoni, and S. Pieri, "Studies on canine leishmaniasis control. 1. Evolution of infection of different clinical forms of canine leishmaniasis following antimonial 
treatment," Transactions of the Royal Society of Tropical Medicine and Hygiene, vol. 82, no. 4, pp. 566-567, 1988.

[93] A. F. Koutinas and C. K. Koutinas, "Pathologic mechanisms underlying the clinical findings in canine Leishmaniosis due to Leishmania infantum/chagasi," Veterinary Pathology, vol. 51, no. 2, pp. 527-538, 2014.

[94] W. G. Lima, M. S. M. Michalick, M. N. D. Melo, W. L. Tafuri, and W. L. Tafuri, "Canine visceral leishmaniasis: A histopathological study of lymph nodes," Acta Tropica, vol. 92, no. 1, pp. 43-53, 2004.

[95] V. Foglia Manzillo, T. Di Muccio, S. Cappiello et al., "Prospective study on the incidence and progression of clinical signs in naïve dogs naturally infected by Leishmania infantum," PLOS Neglected Tropical Diseases, vol. 7, no. 5, Article ID e2225, 2013.

[96] L. Ferrer, R. Rabanal, D. Fondevila, J. A. Ramos, and M. Domingo, "Skin lesions in canine leishmaniasis," Journal of Small Animal Practice, vol. 29, no. 6, pp. 381-388, 1988.

[97] X. Roura, A. Fondati, G. Lubas et al., "Prognosis and monitoring of leishmaniasis in dogs: A working group report," The Veterinary Journal, vol. 198, no. 1, pp. 43-47, 2013.

[98] L. Ordeix, A. Dalmau, M. Osso, J. Llull, S. Montserrat-Sangrà, and L. Solano-Gallego, "Histological and parasitological distinctive findings in clinically-lesioned and normal-looking skin of dogs with different clinical stages of leishmaniosis," Parasites \& Vectors, vol. 10, no. 1, article no. 121, 2017.

[99] S. D. Pietro, V. R. Francesca Bosco, C. Crinò, F. Francaviglia, and E. Giudice, "Prevalence, type, and prognosis of ocular lesions in shelter and owned-client dogs naturally infected by Leishmania infantum," Veterinary World, vol. 9, no. 6, pp. 633-637, 2016.

[100] S. Sbrana, V. Marchetti, F. Mancianti, G. Guidi, and D. Bennett, "Retrospective study of 14 cases of canine arthritis secondary toLeishmania infection," Journal of Small Animal Practice, vol. 55, no. 6, pp. 309-313, 2014.

[101] A. P. Giannuzzi, M. Ricciardi, A. De Simone, and F. Gernone, "Neurological manifestations in dogs naturally infected by Leishmania infantum: descriptions of 10 cases and a review of the literature," Journal of Small Animal Practice, vol. 58, no. 3, pp. 125-138, 2017.

[102] D. Proverbio, "The use of two clinical staging systems of canine leishmaniasis in a clinical setting: a critical evaluation," Journal of Veterinary Clinical Practice and Petcare, pp. 1-3, 2016.

[103] L. Solano-Gallego, A. Koutinas, G. Miró et al., "Directions for the diagnosis, clinical staging, treatment and prevention of canine leishmaniosis," Veterinary Parasitology, vol. 165, no. 1-2, pp. 1-18, 2009.

[104] S. Paltrinieri, L. Solano-Gallego, A. Fondati et al., "Guidelines for diagnosis and clinical classification of leishmaniasis in dogs," Journal of the American Veterinary Medical Association, vol. 236, no. 11, pp. 1184-1191, 2010.

[105] O. Courtenay, R. J. Quinnell, L. M. Garcez, J. J. Shaw, and C. Dye, "Infectiousness in a cohort of Brazilian dogs: why culling fails to control visceral leishmaniasis in areas of high transmission," The Journal of Infectious Diseases, vol. 186, no. 9, pp. 1314-1320, 2002.

[106] O. Courtenay, C. Carson, L. Calvo-Bado, L. M. Garcez, and R. J. Quinnell, "Heterogeneities in Leishmania infantum infection: using skin parasite burdens to identify highly infectious dogs," PLOS Neglected Tropical Diseases, vol. 8, no. 1, 2014.

[107] M. D. Laurenti, C. N. Rossi, V. L. R. D. Matta et al., "Asymptomatic dogs are highly competent to transmit Leishmania (Leishmania) infantum chagasi to the natural vector," Veterinary Parasitology, vol. 196, no. 3-4, pp. 296-300, 2013.
[108] J. Alvar, C. Cañavate, R. Molina, J. Moreno, and J. Nieto, "Canine leishmaniasis," Advances in Parasitology, vol. 57, pp. 1-88, 2004.

[109] P. M. Kaye and T. Aebischer, "Visceral leishmaniasis: Immunology and prospects for a vaccine," Clinical Microbiology and Infection, vol. 17, no. 10, pp. 1462-1470, 2011.

[110] F. Y. Liew and C. A. O’Donnell, "Immunology of leishmaniasis," Advances in Parasitology, vol. 32, pp. 161-259, 1993.

[111] S. Hosein, D. P. Blake, and L. Solano-Gallego, "Insights on adaptive and innate immunity in canine leishmaniosis," Parasitology, vol. 144, no. 1, pp. 95-115, 2017.

[112] C. L. Barbiéri, "Immunology of canine leishmaniasis," Parasite Immunology, vol. 28, no. 7, pp. 329-337, 2006.

[113] T. C. B. de Vasconcelos, M. C. Furtado, V. S. Belo, F. N. Morgado, and F. B. Figueiredo, "Canine susceptibility to visceral leishmaniasis: A systematic review upon genetic aspects, considering breed factors and immunological concepts," Infection, Genetics and Evolution, 2017.

[114] R. J. Quinnell, L. J. Kennedy, A. Barnes et al., "Susceptibility to visceral leishmaniasis in the domestic dog is associated with MHC class II polymorphism," Immunogenetics, vol. 55, no. 1, pp. 23-28, 2003.

[115] E. Sanchez-Robert, L. Altet, A. Sanchez, and O. Francino, "Polymorphism of Slcllal (Nramp1) gene and canine leishmaniasis in a case-control study," Journal of Heredity, vol. 96, no. 7, pp. 755758, 2005.

[116] E. Sanchez-Robert, L. Altet, M. Utzet-Sadurni, U. Giger, A. Sanchez, and O. Francino, "Slcllal (formerly Nramp1) and susceptibility to canine visceral leishmaniasis," Veterinary Research, vol. 39, no. 3, article no. 36, 2008.

[117] L. Solano-Gallego, J. Llull, G. Ramos et al., "The Ibizian hound presents a predominantly cellular immune response against natural Leishmania infection," Veterinary Parasitology, vol. 90, no. 1-2, pp. 37-45, 2000.

[118] V. S. Belo, C. J. Struchiner, G. L. Werneck et al., "A systematic review and meta-analysis of the factors associated with Leishmania infantum infection in dogs in Brazil," Veterinary Parasitology, vol. 195, no. 1-2, pp. 1-13, 2013.

[119] F. L. Burillo, F. M. G. Pérez, J. P. Lieza, M. C. A. Fabián, and F. M. G. Pérez, "Iron status and anemia in canine leishmaniasis," Revue Médecine Vétérinaire, vol. 145, no. 3, pp. 171-176, 1994.

[120] R. De Luna, M. Ferrante, L. Severino et al., "Decreased lipid fluidity of the erythrocyte membrane in dogs with leishmaniasisassociated anaemia," Journal of Comparative Pathology, vol. 122, no. 2-3, pp. 213-216, 2000.

[121] I. Amusategui, A. Sainz, F. Rodríguez, and M. A. Tesouro, "Distribution and relationships between clinical and biopathological parameters in canine leishmaniasis," European Journal of Epidemiology, vol. 18, no. 2, pp. 147-156, 2003.

[122] A. B. Reis, O. A. Martins-Filho, A. Teixeira-Carvalho et al., "Parasite density and impaired biochemical/hematological status are associated with severe clinical aspects of canine visceral leishmaniasis," Research in Veterinary Science, vol. 81, no. 1, pp. 68-75, 2006.

[123] S. Paltrinieri, L. Gradoni, X. Roura, A. Zatelli, and E. Zini, "Laboratory tests for diagnosing and monitoring canine leishmaniasis," Veterinary Clinical Pathology, vol. 45, no. 4, pp. 552578, 2016.

[124] M. Heidarpour, S. Soltani, M. Mohri, and J. Khoshnegah, "Canine visceral leishmaniasis: Relationships between oxidative stress, liver and kidney variables, trace elements, and clinical status," Parasitology Research, vol. 111, no. 4, pp. 1491-1496, 2012. 
[125] W. L. Tafuri, M. R. De Oliveira, M. N. Melo, and W. L. Tafuri, "Canine visceral leishmaniosis: A remarkable histopathological picture of one case reported from Brazil," Veterinary Parasitology, vol. 96, no. 3, pp. 203-212, 2001.

[126] S. Sundar and M. Rai, "Laboratory diagnosis of visceral leishmaniasis," Clinical and Diagnostic Laboratory Immunology, vol. 9, no. 5, pp. 951-958, 2002.

[127] S. M. Barrouin-Melo, D. F. Larangeira, J. Trigo, P. H. P. Aguiar, W. L. C. Dos-Santos, and L. Pontes-De-Carvalho, "Comparison between splenic and lymph node aspirations as sampling methods for the parasitological detection of Leishmania chagasi infection in dogs," Memórias do Instituto Oswaldo Cruz, vol. 99, no. 2, pp. 195-197, 2004.

[128] R. C. Silva, V. B. Richini-Pereira, M. Kikuti, P. M. Marson, and H. Langoni, "Detection of Leishmania (L.) infantum in stray dogs by molecular techniques with sensitive species-specific primers," Veterinary Quarterly, vol. 37, no. 1, pp. 23-30, 2017.

[129] L. Solano-Gallego, A. Rodriguez-Cortes, M. Trotta et al., "Detection of Leishmania infantum DNA by fret-based realtime PCR in urine from dogs with natural clinical leishmaniosis," Veterinary Parasitology, vol. 147, no. 3-4, pp. 315-319, 2007.

[130] E. D. C. Ferreira, M. de Lana, M. Carneiro et al., "Comparison of serological assays for the diagnosis of canine visceral leishmaniasis in animals presenting different clinical manifestations," Veterinary Parasitology, vol. 146, no. 3-4, pp. 235-241, 2007.

[131] R. Porrozzi, M. V. Santos Da Costa, A. Teva et al., "Comparative evaluation of enzyme-linked immunosorbent assays based on crude and recombinant leishmanial antigens for serodiagnosis of symptomatic and asymptomatic Leishmania infantum visceral infections in dogs," Clinical and Vaccine Immunology, vol. 14, no. 5, pp. 544-548, 2007.

[132] E. G. Lopes, A. P. Sevá, F. Ferreira et al., "Serological and molecular diagnostic tests for canine visceral leishmaniasis in Brazilian endemic area: one out of five seronegative dogs are infected," Epidemiology and Infection, pp. 1-9, 2017.

[133] D. B. M. Fraga, L. V. Pacheco, L. S. Borja et al., "The rapid test based on Leishmania infantum chimeric rK28 protein improves the diagnosis of canine visceral leishmaniasis by reducing the detection of false-positive dogs," PLOS Neglected Tropical Diseases, vol. 10, no. 1, Article ID e0004333, 2016.

[134] L. Manna, R. Corso, G. Galiero, A. Cerrone, P. Muzj, and A. E. Gravino, "Long-term follow-up of dogs with leishmaniosis treated with meglumine antimoniate plus allopurinol versus miltefosine plus allopurinol," Parasites \& Vectors, vol. 8, no. 1, article no. 289, 2015.

[135] D. Yasur-Landau, C. L. Jaffe, L. David, and G. Baneth, "Allopurinol resistance in Leishmania infantum from dogs with disease relapse," PLOS Neglected Tropical Diseases, vol. 10, no. 1, Article ID e0004341, 2016.

[136] L. Solano-Gallego, L. Di Filippo, L. Ordeix et al., "Early reduction of Leishmania infantum-specific antibodies and blood parasitemia during treatment in dogs with moderate or severe disease," Parasites \& Vectors, vol. 9, article 235, 2016.

[137] M. Torres, J. Pastor, X. Roura et al., "Adverse urinary effects of allopurinol in dogs with leishmaniasis," Journal of Small Animal Practice, vol. 57, no. 6, pp. 299-304, 2016.

[138] D. Sabaté, J. Llinás, J. Homedes, M. Sust, and L. Ferrer, "A single-centre, open-label, controlled, randomized clinical trial to assess the preventive efficacy of a domperidone-based treatment programme against clinical canine leishmaniasis in a high prevalence area," Preventive Veterinary Medicine, vol. 115, no. 1-2, pp. 56-63, 2014.
[139] S. M. Da Silva, I. F. G. Amorim, R. R. Ribeiro et al., "Efficacy of combined therapy with liposome-encapsulated meglumine antimoniate and allopurinol in treatment of canine visceral leishmaniasis," Antimicrobial Agents and Chemotherapy, vol. 56, no. 6, pp. 2858-2867, 2012.

[140] B. Davoust, C. Roqueplo, D. Parzy, S. Watier-Grillot, and J.-L. Marié, "A twenty-year follow-up of canine leishmaniosis in three military kennels in southeastern France," Parasites \& Vectors, vol. 6, no. 1, article 323, 2013.

[141] D. Otranto, D. de Caprariis, R. P. Lia et al., "Prevention of endemic canine vector-borne diseases using imidacloprid $10 \%$ and permethrin $50 \%$ in young dogs: A longitudinal field study," Veterinary Parasitology, vol. 172, no. 3-4, pp. 323-332, 2010.

[142] E. Brianti, G. Gaglio, and E. Napoli, "Efficacy of a slow-release imidacloprid (10\%)/flumethrin (4.5\%) collar for the prevention of canine leishmaniasis," Parasites \& Vectors, vol. 7, no. 327, 2014.

[143] C. E. Wylie, M. Carbonell-Antoñanzas, E. Aiassa et al., "A systematic review of the efficacy of prophylactic control measures for naturally occurring canine leishmaniosis. Part II: Topically applied insecticide treatments and prophylactic medications," Preventive Veterinary Medicine, vol. 117, no. 1, pp. 19-27, 2014.

[144] C. B. Fernandes, J. T. M. Junior, C. de Jesus et al., "Comparison of two commercial vaccines against visceral leishmaniasis in dogs from endemic areas: IgG, and subclasses, parasitism, and parasite transmission by xenodiagnosis," Vaccine, vol. 32, no. 11, pp. 1287-1295, 2014.

[145] C. H. Costa and J. B. Vieira, "Changes in the control program of visceral leishmaniasis in Brazil.," Journal of the Brazilian Society of Tropical Medicine, vol. 34, no. 2, pp. 223-228, 2001.

[146] G. A. S. Romero and M. Boelaert, "Control of visceral leishmaniasis in latin America - A systematic review," PLOS Neglected Tropical Diseases, vol. 4, no. 1, article no. e584, 2010. 


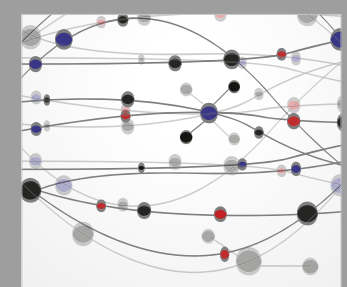

The Scientific World Journal
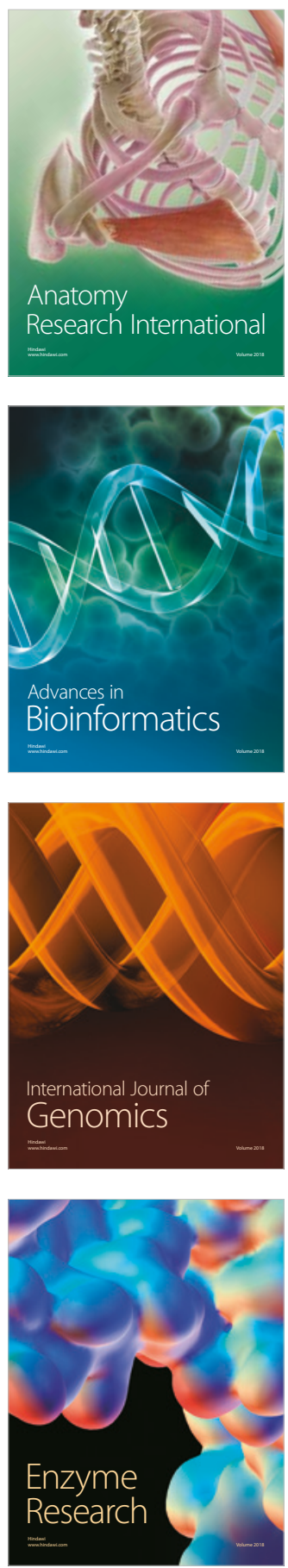
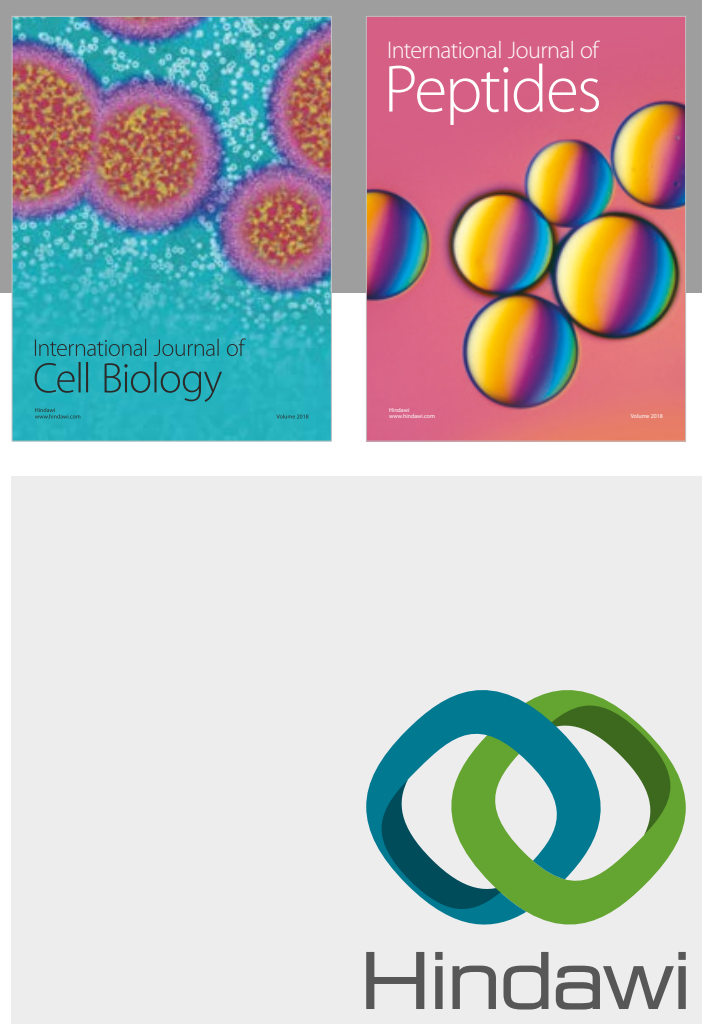

Submit your manuscripts at

www.hindawi.com
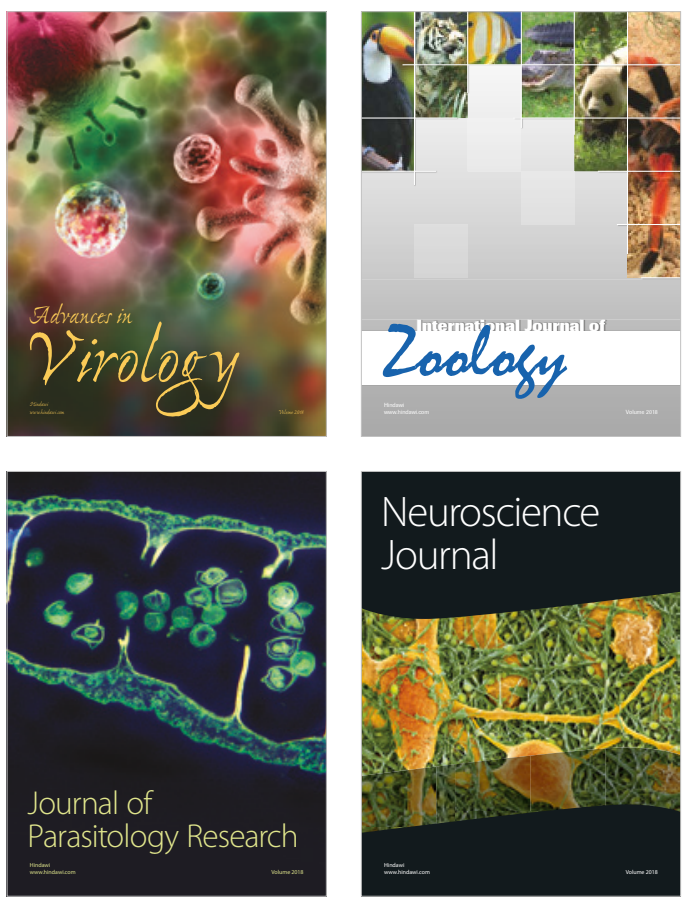
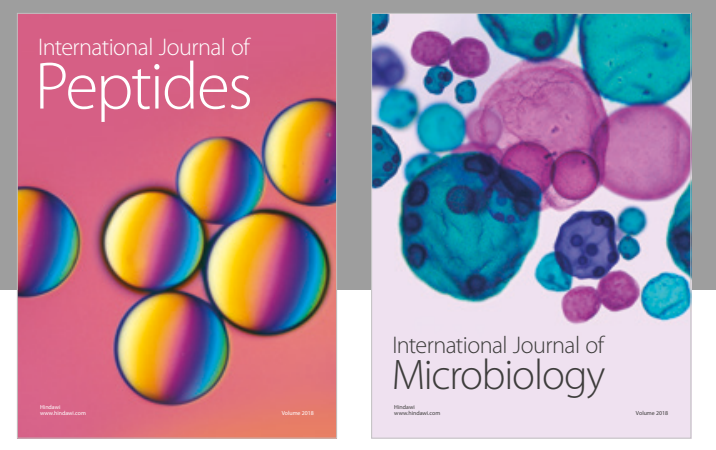

nternational Journal of Microbiology
Journal of
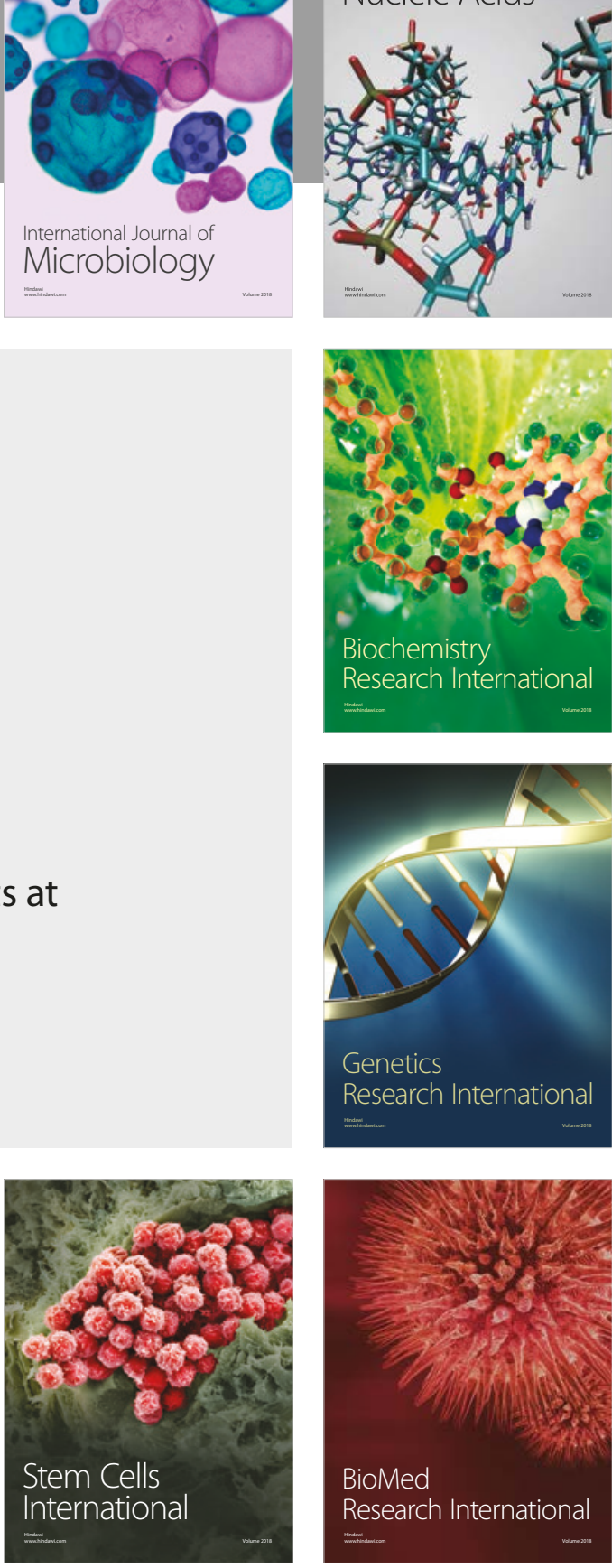
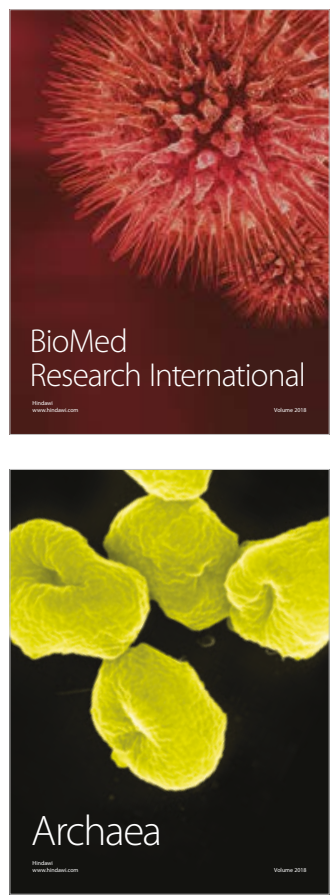